International Journal of Medical Anesthesiology 2019; 2(2): 106-111

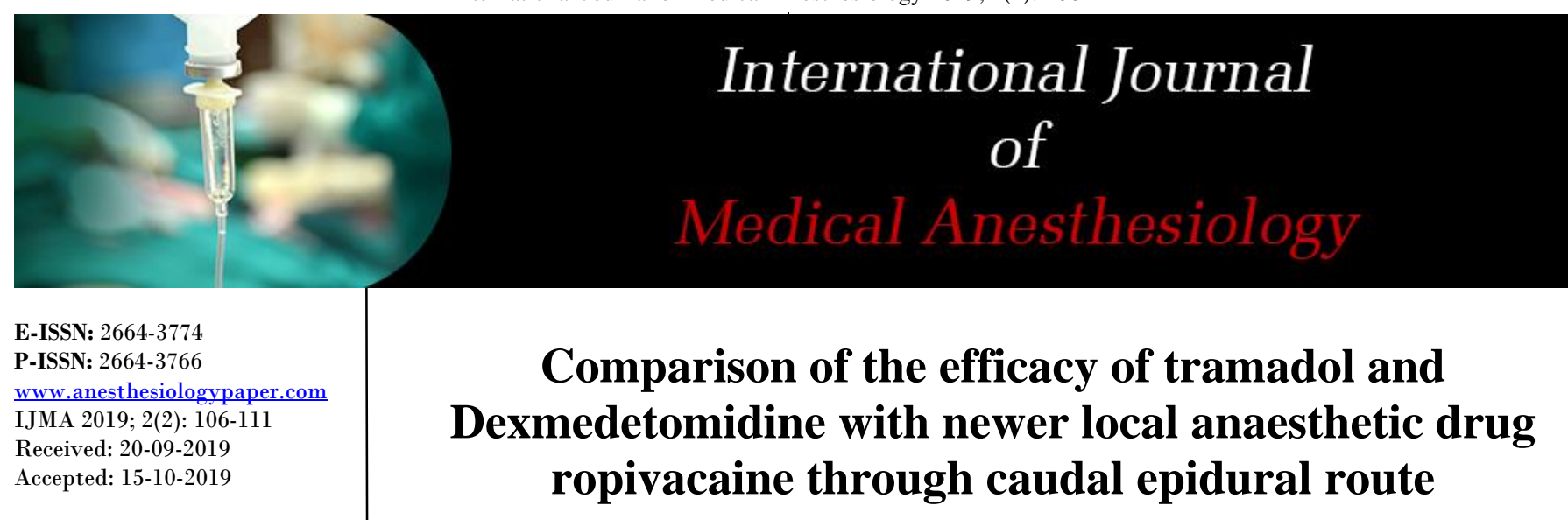

Dr. Sneha B Ameen Assistant Professor, Department of Anaesthesia, GMERS Medical College, Himmatnagar, Gujarat, India

\section{Dr. Bharti Rajani}

Associate Professor,

Department of Anaesthesia,

GMERS Medical College,

Gandhinagar, Gujarat, India
Corresponding Author: Dr. Bharti Rajani Associate Professor, Department of Anaesthesia, GMERS Medical College, Gandhinagar, Gujarat, India

\section{Dr. Sneha B Ameen and Dr. Bharti Rajani}

DOI: https://doi.org/10.33545/26643766.2019.v2.i2b.39

\section{Abstract}

Background: Caudal analgesia is a form of caudal epidural block commonly used technique for surgical anaesthesia in children and chronic pain management in adults. It is performed by inserting a needle through the sacral hiatus to gain entrance into the sacral epidural space.

Materials \& Methods: The present article involves postoperative caudal analgesia study in 80 ASA III paediatric patients undergoing infraumbilical surgeries by comparing two drugs, tramadol \& dexmeditomidine with ropivacaine in paediatric patients. Here the 80 patients were divided in two groups (group T: Tramadol, group D: Dexmedetomidine). Quality of pain relief and sedation was assessed by FLACC score and Modified Ramsay Sedation score respectively for both the groups.

Results: Addition of Dexmedetomidine with Ropivacaine leads to increased duration of analgesia when compared to Tramadol for paediatric infraumbilical surgeries \& reduces the postoperative analgesic requirements in $1^{\text {st }} 24 \mathrm{hrs}$. with, initial better quality of sleep.

Keywords: caudal analgesia, ropivacaine, tramadol, Dexmedetomidine

\section{Introduction}

Regional analgesic are now a days commonly used \& effective techniques for postoperative analgesia in paediatric patients. Caudal epidural analgesia is currently most popular and commonly performed analgesic technique used for paediatric patients. Caudal analgesia is essentially a form of epidural analgesia obtained by blocking spinal nerves in caudal space. It has been used for various surgeries like obstetrical, gynaecological, perineal, infraumbilical, lower abdominal \& lower limb surgeries ${ }^{[1]}$.

Various drugs have been used for caudal analgesia like bupivacaine, tramadol, dexmedetomidine, ropivacaine, fentanyl etc but very few studies have compared their analgesic effect by caudal epidural route.

Ropivacaine is a long-acting regional anaesthetic that is structurally related to Bupivacaine. It is a pure $\mathrm{S}(-)$ enantiomer, unlike Bupivacaine which is a racemate, developed for the purpose of reducing potential toxicity and improving relative sensory and motor block profiles. Ropivacaine causes reversible inhibition of $\mathrm{Na}$ ion influx and thereby blocks impulse generation and conduction in nerve fibres, by slowing the propagation of the nerve impulse and by reducing the rate of rise of the action potential. This action is potentiated by dose-dependent inhibition of potassium channels. Ropivacaine is less lipophilic than bupivacaine and is less likely to penetrate large myelinated motor fibres; therefore, it has selective action on the pain-transmitting $\mathrm{A} \delta$ and $\mathrm{C}$ nerve fibres rather than $\mathrm{A} \beta$ fibres, which are involved in motor function ${ }^{[2,3]}$.

Tramadol, a synthetic opioid of the aminocyclohexanol group, is a unique analgesic that acts at multiple sites, providing moderate pain relief. Tramadol acts as a $\mu$-opioid receptor agonist, serotonin releasing agent, norepinephrine reuptake inhibitor, NMDA receptor antagonist, 5HT 2c receptor antagonist, (a 7)5 nicotinic acetylcholine receptor antagonist, and $\mathrm{M} 1$ and M3 muscarinic acetylcholine receptor antagonist ${ }^{[4,5]}$.

Dexmedetomidine is the dextro-rotatory S-enantiosmer of dexmedetomidine. Analgesia is provided through binding of Dexmedetomidine to alpha2-adrenoceptors in the spinal cord. The $\alpha 2$ produce their sedative-hypnotic effect by an action on $\alpha 2$ receptors in the locus caeruleus and within the spinal cord ${ }^{[7]}$.

Literature survey reveals that Ropivacaine, Dexmedetomidine and Tramadol were individually used for short-term sedation and analgesia as well as in combination with other drugs since many years. Tramadol in combination with Bupivacaine also is a successful co- 
therapy for caudal analgesia in children aged 12-84 months. But the main disadvantage of caudal anaesthesia is short duration of action after single injection of local anaesthetic solution. Even long-acting local anaesthetic drug such as Bupivacaine provide only 4-8 hrs. of analgesia. Also literature survey reveals that addition Dexmedetomidine or Tramadol or Fentanyl to Bupivacaine for caudal blocks in children would prolong postoperative pain relief and reduce the need for additional analgesics thus allowing single shot caudal analgesia to be recommended for surgery lasting more than $90 \mathrm{~min}$. To improve the duration of analgesia it was rationalized to compare the efficacy of tramadol and dexmedetomidine as an additives with newer local anaesthetic drug ropivacaine through caudal epidural route [8-12].

The aim of the study was to compare the efficacy of tramadol and dexmedetomidine as an additive with newer local anaesthetic drug ropivacaine through caudal epidural route in paediatric patients undergoing infra-umbilical urological surgeries. The study involves comparison of duration of analgesia and sedation along with total dose of rescue analgesic with subsequent study of side effects.

\section{Methodology}

This was a randomized double bling study in a tertiary care teaching hospital. The study protocol was approved by the institutional ethics committee. The type and nature of the study was clearly explained to the parents/legal guardians of the paediatric patients in the local language and they were given opportunity to ask questions for the same. Written informed consent was obtained from all patients' parent/legal guardian before enrolling them for the study.

\section{Patient inclusion and exclusion criteria}

Patient inclusion criteria includes ASA grade I or II, Age: 210 years, Surgery: Infraumbilical urogenital surgeries and Weight: 8-20kgs.

Patient exclusion criteria includes Neuromuscular/ spinal diseases, local infection at site of caudal injection, Sacral anomalies, Coagulation abnormality, Mental retardation (congenital anomaly), Allergic to drugs, Caudal space is not located properly.

\section{Randomization and blinding}

The study was conducted on 80 paediatric patients who were randomly allocated into two groups (group $\mathrm{T}$ : Tramadol, group D: Dexmedetomidine) of 40 patients each using computer generated random number table. Anaesthetic drugs were prepared by the separate anaesthesiologist who is not involved in the operative procedure so that patients and concerned anaesthetist were not aware about the drug details. As it was an open lable study, no blinding was followed.

Materials Used: Inj Ropivacaine $0.2 \% \quad(0.5 \mathrm{ml} / \mathrm{kg})$, Inj Tramadol (2mg/kg) volume: $1 \mathrm{ml}$; Inj Dexmedetomidine $(2 \mathrm{mcg} / \mathrm{kg})$ volume: $1 \mathrm{ml}$

\section{Study procedure}

All patients were subjected to preanaestheticcheck up the day before surgery and all routine investigations were noted. Patients were kept for NBM for at least 6 hours for solid food. After applying standard monitors (ECG, NIBP, $\mathrm{SpO}_{2}$ ), under Sevoflurane inhalation, an intravenous cannula was secured and crystalloid like Ringer's lactate solution or DNS solution was given. General anaesthesia was given with premedication of inj. Glycopyrrolate $0.004 \mathrm{mg} / \mathrm{kg}$ and Inj Fentanyl $2 \mu \mathrm{g} / \mathrm{kg}$. Preoxygenation was started with $100 \%$ $\mathrm{O} 2$ for 3minutes along with Induction with inj. of Thiopentone $5-7 \mathrm{mg} / \mathrm{kg}$ and inj. Of Succinylcholine $2 \mathrm{mg} / \mathrm{kg}$. Also patients were subjected to Laryngoscopy followed by endotracheal intubation and Maintainance of $\mathrm{O}_{2}, \mathrm{~N}_{2} \mathrm{O}$, sevoflurane/isofluraneg and atracurium. After Induction, patients were put in left lateral position with knee and hip joints of both legs flexed.

\section{Technique of anesthesia}

Under full aseptic precautions, sacral cornue were palpated \& sacral hiatus was identified. $22 \mathrm{G}$ hypodermic needle was inserted in the midline in between the two sacral cornue through the sacral hiatus at an angle of $45^{\circ}$ with the skin \& directed cranially to penetrate the sacrococcygeal membrane. The penetration of sacrococcygeal membrane was felt as 'loss of resistance' or as 'give in' sensation. Then the needle was depressed i.e. the angle reduced, almost flush with the skin covering sacrum. The needle was advanced for almost $2 \mathrm{~cm}$ into the sacral canal. After negative aspiration for blood \& CSF, InjRopivacaine $0.2 \%$ $(0.5 \mathrm{ml} / \mathrm{kg})$ with Inj Tramadol $(2 \mathrm{mg} / \mathrm{kg})$ or Inj Dexmedetomidine $(2 \mathrm{mcg} / \mathrm{kg})$ in one $\mathrm{ml}$ volume was given according to random allocation of the patients in Group $\mathrm{T}$ or Group D respectively.

\section{Surgical procedure and monitoring}

Surgery was started in supine position. Haemodynamic monitoring (HR, BP, SPO2) was done every 15 minutes. Thermoregulation was maintained during surgery. Fluid was given according to hollidaysegar formula. After return of spontaneous respiration, patients were reversed with inj. neostigmine $0.05 \mathrm{mg} / \mathrm{kg}+$ inj. glycopyrrolate $0.008 \mathrm{mg} / \mathrm{kg}$. Patients were extubated after adequate muscle tone and good respiratory effort. Patients were observed for 24 hours postoperatively in recovery room. Quality of pain relief was assessed by FLACC score. FLACC score measured every 4 hourly postoperatively. When the pain score was > 4, intravenous Tramadol $1 \mathrm{mg} / \mathrm{kg}$ was given as a rescue analgesic and duration of caudal analgesia was noted. Total dose of inj. tramadol required during 24 hours was also noted. Sedation was assessed by Modified Ramsay Sedation score every hourly for 6 hours in recovery room.

\section{Statistical Analysis}

All Collected data are entered into the Microsoft excel 2010. Continuous data are expressed as mean \pm SD form. Independent $t$ test and Mann Whitney test have been used for carrying out significant P-value. Non-Continuous data are countable and are expressed as in frequency or in percentages. Chi Square test and Fisher Exact test have been used for carrying out significant P-value.

\section{Results}

This prospective double blind study was carried out on 80 ASA I-II paediatric patients undergoing infraumbilical surgeries for postoperative analgesia. 
Table 1: Demographic Data

\begin{tabular}{|c|c|c|c|}
\hline & Group D & Group T & P-value \\
\hline Age (n=40) & $3.55 \pm 1.43$ & $3.70 \pm 1.65$ & 0.79 \\
\hline Sex $:$ M/F & $32 / 8$ & $31 / 9$ & 0.79 \\
\hline Weight (kg) & $13.03 \pm 2.99$ & $12.53 \pm 2.54$ & 0.62 \\
\hline Mean Duration of surgery (hrs.) & $3.83 \pm 0.71$ & $3.80 \pm 0.79$ & 0.22 \\
\hline
\end{tabular}

(Group T: Tramadol, Group D: Dexmedetomidine)

The patients in the study were demographically comparable in both the groups D and T. The mean age for group D was $3.55 \pm 1.43$ and for group $\mathrm{T}$ was $3.70 \pm 1.65$. The $\mathrm{P}$-value indicates no statistical significant difference in both the groups with regard to Age, Sex, Weight \& Duration of surgery.

Table 2: Types of Surgery

\begin{tabular}{|c|c|c|c|}
\hline & Group D & Group T & P-value \\
\hline Hypospadias repair & $13(32.5 \%)$ & $12(30 \%)$ & 0.81 \\
\hline Orchidopexy & $2(5 \%)$ & $1(2.5 \%)$ & 0.99 \\
\hline Ureteric reimplant & $21(52.5 \%)$ & $22(55 \%)$ & 0.82 \\
\hline Urethrocutaneous fistula closure & $1(2.5 \%)$ & - & 0.99 \\
\hline Vesicostomy & $3(7.5 \%)$ & $5(12.5 \%)$ & 0.71 \\
\hline
\end{tabular}

(Group T: Tramadol, Group D: Dexmedetomidine)

In present study we have selected only infra-umbilical surgeries \& most of the surgeries were Open ureteric reimplantation $\&$ hypospadias repair.

Table 3: Intraoperative Pulse Rate

\begin{tabular}{|c|c|c|c|}
\hline & $\begin{array}{c}\text { Group D } \\
\text { Mean } \pm \text { SD }\end{array}$ & $\begin{array}{c}\text { Group T } \\
\text { Mean } \pm \text { SD }\end{array}$ & P-value \\
\hline $0 \mathrm{~min}$ & $146.85 \pm 11.10$ & $146.78 \pm 10.46$ & 0.98 \\
\hline $15 \mathrm{~min}$ & $139.93 \pm 11.05$ & $140.00 \pm 10.01$ & 0.98 \\
\hline $30 \mathrm{~min}$ & $134.18 \pm 11.22$ & $134.08 \pm 8.65$ & 0.97 \\
\hline $45 \mathrm{~min}$ & $129.10 \pm 9.96$ & $127.83 \pm 7.28$ & 0.52 \\
\hline $1 \mathrm{hr}$ & $122.83 \pm 9.45$ & $122.55 \pm 5.59$ & 0.88 \\
\hline $2 \mathrm{hr}$ & $116.45 \pm 9.15$ & $117.63 \pm 5.55$ & 0.57 \\
\hline $4 \mathrm{hr}$ & $110.10 \pm 8.31$ & $112.38 \pm 6.30$ & 0.23 \\
\hline $6 \mathrm{hr}$ & $104.75 \pm 6.13$ & $98.50 \pm 0.71$ & 0.13 \\
\hline
\end{tabular}

(Group T: Tramadol, Group D: Dexmedetomidine)

The mean intra-operative pulse rate at baseline for group D was $146.85 \pm 11.10$ and Group T was $146.78 \pm 10.46$ and after 6 hours it was $104.75 \pm 6.13$ and $98.50 \pm 0.71$ for group D and group $\mathrm{T}$ respectively. The $\mathrm{P}$-value indicates no statistical significant difference in both the groups with regard to Intra-operative pulse rate at different time intervals during surgery.

Table 4: Intraoperative Blood Pressure

\begin{tabular}{|c|c|c|c|}
\hline & Group D (N=40) & Group T (N=40) & P-value \\
\hline $0 \mathrm{~m}$ & $100.88 \pm 4.16$ & $101.60 \pm 4.30$ & 0.45 \\
\hline & $67.38 \pm 3.92$ & $69.00 \pm 3.27$ & 0.05 \\
\hline $15 \mathrm{~m}$ & $98.73 \pm 1.57$ & $99.15 \pm 0.62$ & 0.09 \\
\hline & $65.13 \pm 4.05$ & $65.60 \pm 4.47$ & 0.48 \\
\hline $30 \mathrm{~m}$ & $96.48 \pm 3.68$ & $97.78 \pm 2.69$ & 0.08 \\
\hline & $62.10 \pm 5.90$ & $63.28 \pm 4.70$ & 0.50 \\
\hline $45 \mathrm{~m}$ & $95.78 \pm 3.45$ & $96.25 \pm 3.89$ & 0.26 \\
\hline & $60.58 \pm 4.94$ & $61.30 \pm 4.15$ & 0.87 \\
\hline $1 \mathrm{hr}$ & $93.00 \pm 3.46$ & $94.30 \pm 4.27$ & 0.12 \\
\hline & $58.03 \pm 5.38$ & $58.95 \pm 4.84$ & 0.69 \\
\hline $2 \mathrm{hr}$ & $90.40 \pm 1.89$ & $91.45 \pm 3.29$ & 0.40 \\
\hline & $57.55 \pm 4.99$ & $58.35 \pm 4.85$ & 0.73 \\
\hline $4 \mathrm{hr}$ & $90.00 \pm 0.72$ & $90.38 \pm 1.88$ & 0.79 \\
\hline & $55.08 \pm 4.84$ & $57.35 \pm 4.04$ & 0.07 \\
\hline
\end{tabular}

(Group T: Tramadol, Group D: Dexmedetomidine)
The P-value indicates no statistical significant difference in both the groups with regard to Intra-operative blood pressure at different time intervals during surgery.

Table 5: Post-operative Pulse rate

\begin{tabular}{|c|c|c|c|}
\hline & Group D (N=40) & Group T $(\mathbf{N = 4 0 )}$ & P-value \\
\hline $0 \mathrm{~m}$ & $136.85 \pm 15.80$ & $141.55 \pm 15.41$ & 0.18 \\
\hline $1 \mathrm{hr}$ & $127.53 \pm 14.77$ & $133.98 \pm 14.34$ & 0.05 \\
\hline $4 \mathrm{hr}$ & $123.65 \pm 13.32$ & $127.83 \pm 12.30$ & 0.15 \\
\hline $8 \mathrm{hr}$ & $118.00 \pm 11.12$ & $123.30 \pm 12.45$ & 0.05 \\
\hline $12 \mathrm{hr}$ & $115.00 \pm 9.32$ & $118.78 \pm 11.54$ & 0.11 \\
\hline $16 \mathrm{hr}$ & $110.70 \pm 7.82$ & $113.68 \pm 10.52$ & 0.15 \\
\hline $20 \mathrm{hr}$ & $106.33 \pm 6.58$ & $108.80 \pm 9.07$ & 0.17 \\
\hline $24 \mathrm{hr}$ & $104.90 \pm 8.49$ & $105.53 \pm 7.39$ & 0.72 \\
\hline
\end{tabular}

(Group T: Tramadol, Group D: Dexmedetomidine)

The mean post-operative pulse rate at baseline for group D was $136.85 \pm 15.80$ and Group $\mathrm{T}$ was $141.55 \pm 15.41$ and after 24 hours it was $104.90 \pm 8.49$ and $105.53 \pm 7.39$ for group D and group $\mathrm{T}$ respectively. The $\mathrm{P}$-value indicates no statistical significant difference in both the groups with regard to Postoperative Pulse rate at different time intervals after surgery.

Table 6: Postoperative Blood Pressure

\begin{tabular}{|c|c|c|c|}
\hline & Group D (N=40) & Group T (N=40) & P-value \\
\hline $0 \mathrm{~m}$ & $102.30 \pm 7.80$ & $103.58 \pm 7.20$ & 0.14 \\
\hline & $67.75 \pm 7.11$ & $68.80 \pm 3.52$ & 0.42 \\
\hline $1 \mathrm{hr}$ & $100.75 \pm 6.46$ & $101.38 \pm 6.05$ & 0.17 \\
\hline & $68.28 \pm 4.39$ & $68.13 \pm 3.59$ & 0.61 \\
\hline $4 \mathrm{hr}$ & $99.38 \pm 4.36$ & $99.15 \pm 4.39$ & 0.38 \\
\hline & $66.00 \pm 5.15$ & $66.80 \pm 5.19$ & 0.59 \\
\hline $8 \mathrm{hr}$ & $98.10 \pm 2.35$ & $98.30 \pm 3.79$ & 0.10 \\
\hline & $66.45 \pm 6.97$ & $66.75 \pm 4.60$ & 0.17 \\
\hline $12 \mathrm{hr}$ & $95.43 \pm 5.71$ & $97.18 \pm 3.55$ & 0.06 \\
\hline & $64.70 \pm 3.62$ & $65.78 \pm 4.32$ & 0.08 \\
\hline $16 \mathrm{hr}$ & $94.70 \pm 5.78$ & $97.00 \pm 3.29$ & 0.20 \\
\hline & $64.78 \pm 3.64$ & $65.25 \pm 4.35$ & 0.39 \\
\hline $20 \mathrm{hr}$ & $96.30 \pm 4.29$ & $96.40 \pm 3.49$ & 0.21 \\
\hline & $62.90 \pm 4.94$ & $65.15 \pm 4.05$ & 0.11 \\
\hline $24 \mathrm{hr}$ & $96.65 \pm 4.29$ & $96.78 \pm 3.29$ & 0.14 \\
\hline & $64.28 \pm 5.12$ & $65.45 \pm 3.69$ & 0.79 \\
\hline
\end{tabular}

(Group T: Tramadol, Group D: Dexmedetomidine) 
The P-value indicates no statistical significant difference in both the groups with regard to Postoperative Blood Pressure at different time intervals after surgery.

Table 7: FLACC Score

\begin{tabular}{|c|c|c|c|}
\hline & Group D (N=40) & Group T (N=40) & P-value \\
\hline $0 \mathrm{~min}$ & $2.43 \pm 0.71$ & $2.78 \pm 0.42$ & 0.01 \\
\hline $1 \mathrm{hr}$ & $2.15 \pm 0.62$ & $2.78 \pm 0.42$ & $<0.01^{*}$ \\
\hline $4 \mathrm{hr}$ & $2.18 \pm 0.78$ & $2.83 \pm 0.38$ & $<0.01^{*}$ \\
\hline $8 \mathrm{hr}$ & $2.30 \pm 0.82$ & $3.13 \pm 0.40$ & $<0.01^{*}$ \\
\hline $12 \mathrm{hr}$ & $2.43 \pm 1.15$ & $3.88 \pm 0.94$ & $<0.01^{*}$ \\
\hline $16 \mathrm{hr}$ & $2.85 \pm 1.29$ & $3.45 \pm 0.60$ & $0.02^{*}$ \\
\hline $20 \mathrm{hr}$ & $3.48 \pm 0.96$ & $3.33 \pm 0.57$ & 0.39 (NS) \\
\hline $24 \mathrm{hr}$ & $3.03 \pm 0.48$ & $3.18 \pm 0.38$ & 0.16 (NS) \\
\hline
\end{tabular}

(Group T: Tramadol, Group D: Dexmedetomidine)

The P-value indicates statistical significant difference in both the groups with regard to FLACC score at different time intervals which was found to be more in Group T compared to group D.

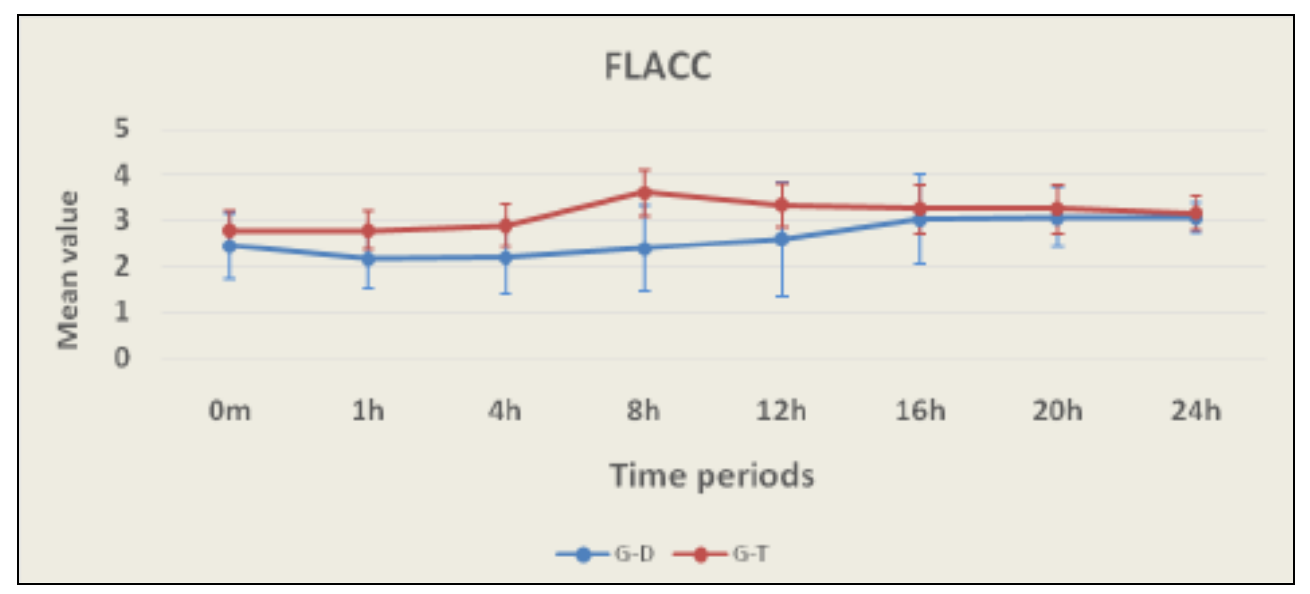

Fig 1: FLACC Score

Table 8: Modified Ramsay Sedation Score

\begin{tabular}{|c|c|c|c|}
\hline & Group D (N=40) & Group T (N=40) & P-value \\
\hline $0 \mathrm{~min}$ & $2.55 \pm 0.81$ & $1.63 \pm 0.49$ & $<0.01^{*}$ \\
\hline $1 \mathrm{hr}$ & $2.35 \pm 0.66$ & $1.68 \pm 0.47$ & $<0.01^{*}$ \\
\hline $4 \mathrm{hr}$ & $2.43 \pm 0.50$ & $1.63 \pm 0.49$ & $<0.01^{*}$ \\
\hline $8 \mathrm{hr}$ & $2.35 \pm 0.48$ & $1.55 \pm 0.50$ & $<0.01^{*}$ \\
\hline $12 \mathrm{hr}$ & $2.18 \pm 0.45$ & $1.38 \pm 0.49$ & $<0.01^{*}$ \\
\hline $16 \mathrm{hr}$ & $1.83 \pm 0.38$ & $1.33 \pm 0.47$ & $<0.01^{*}$ \\
\hline $20 \mathrm{hr}$ & $1.73 \pm 0.45$ & $1.18 \pm 0.38$ & $<0.01^{*}$ \\
\hline $24 \mathrm{hr}$ & $1.80 \pm 0.41$ & $1.30 \pm 0.46$ & $<0.01^{*}$ \\
\hline
\end{tabular}

(Group T: Tramadol, Group D: Dexmedetomidine)

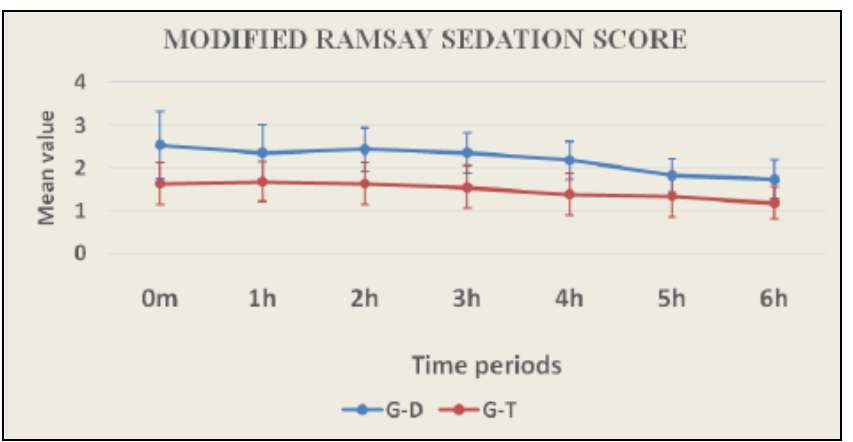

Fig 2: Modified Ramsay Sedation Score

The P-value indicates statistical significant difference in both the groups with regard to Modified Ramsay Sedation score at different time intervals which was found to be less in Group T compared to group D.
Table 9: Rescue Analgesic Consumption

\begin{tabular}{|c|c|c|c|}
\hline & $\begin{array}{c}\text { Group D } \\
(\mathbf{N = 4 0})\end{array}$ & $\begin{array}{c}\text { Group T } \\
(\mathbf{N = 4 0})\end{array}$ & P-alue \\
\hline $\begin{array}{c}\text { Duration of analgesia } \\
\text { (hrs) }\end{array}$ & $17.93 \pm 2.65$ & $12.70 \pm 2.81$ & $<0.01^{*}$ \\
\hline $\begin{array}{c}\text { No. of doses of } \\
\text { Tramadol in 24 hrs }\end{array}$ & $0.85 \pm 0.58$ & $1.55 \pm 0.55$ & $<0.01^{*}$ \\
\hline $\begin{array}{c}\text { Total dose of } \\
\text { Tramadol in 24 hrs }\end{array}$ & $11.28 \pm 8.68$ & $19.73 \pm 8.33$ & $<0.01^{*}$ \\
\hline
\end{tabular}

(Group T: Tramadol, Group D: Dexmedetomidine)

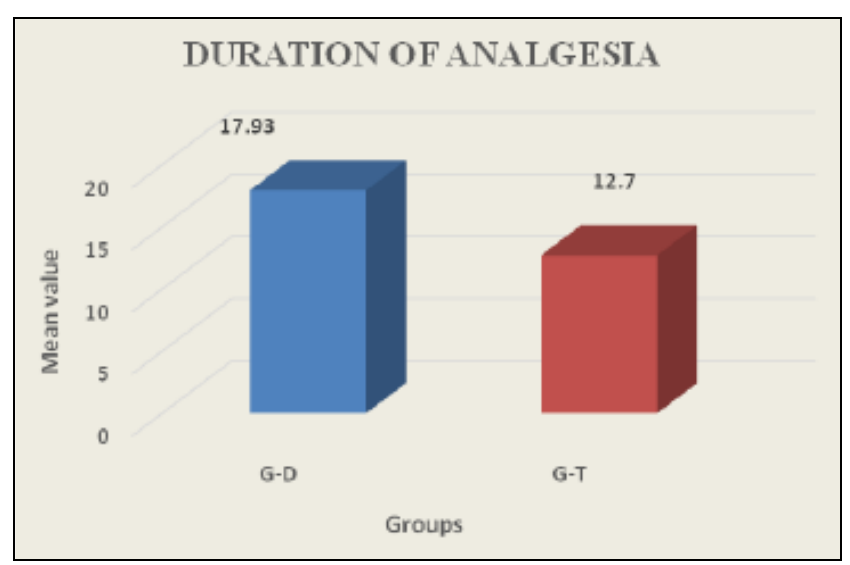

Fig 3: Duration of Analgesia

The duration of analgesia, which is the time from administration of caudal injection of drug to the time when $1 \mathrm{st}$ dose of rescue analgesic i.e. inj.Tramadol $(1 \mathrm{mg} / \mathrm{kg})$ was 
required, is statistically significant between the two groups. Time for $1^{\text {st }}$ dose was $17.93 \pm 2.65$ hrs in group D while it was $12.70 \pm 2.81 \mathrm{hrs}$ in group $\mathrm{T}(P$ value $<0.01)$. The number of doses of rescue analgesic in the form of inj.Tramadol $(1 \mathrm{mg} / \mathrm{kg})$ were $0.85 \pm 0.58$ group $\mathrm{D}$ while in group $\mathrm{T}$ were $1.55 \pm 0.55$ which were statistically significant $(P<0.01)$.

\section{Postoperative complication}

\begin{tabular}{|c|c|c|}
\hline & Group D & Group T \\
\hline Nausea & 0 & 2 \\
\hline Vomiting & 0 & 3 \\
\hline
\end{tabular}

In group T, 2 patient had c/o nausea \& 3 patient had c/o vomiting. Patient had c/o vomiting were treated with inj.ondasetron $0.1 \mathrm{mg} / \mathrm{kg}$.

\section{Discussion}

Pain score can be assessed by various methods in children. We have chosen FLACC Score (Face, Leg, Activity, Crying, Consolability). FLACC Score ranges from 0-10, each patient's pain intensity was assessed at the end of surgery and then every 4 hours for 24 hours after surgery. If the FLACC Score was 4 or more, inj.Tramadol $1 \mathrm{mg} / \mathrm{kg}$ IV as a rescue analgesic was administered. Enteral and parentral analgesics (both opioids and non-opioids), used for providing postoperative analgesia, are associated with risks like gastro-intestinal bleeding, precipitation of asthma, nausea and vomiting, thrombocytopenia, sedation, respiratory depression, hepatotoxicity, nephrotoxicity etc. The regional techniques including the caudal block, avoid most of the problems and it is possible to achieve analgesia with minimum of drug dose and complication ${ }^{[13]}$.

Ropivacaine in comparision to Bupivacaine, has a wide margin of safety, less motor blockade, less cardiovascular or neurological toxicity and similar duration of analgesia. It can be safely used for regional anaesthesia and analgesia in ambulatory setting in paediatrics ${ }^{[14-16]}$.

Dr. Manjushree Ray et al. (2003) ${ }^{[14]}$ compared quality and duration of caudal block produced by Ropivacaine and Bupivacaine \& concluded that Ropivacaine provides effective postoperative analgesia, similar to Bupivacaine but produce less motor blockade as compared to Bupivacaine. G.Ivani et al.(2005) ${ }^{[15]}$ compared Ropivacaine $0.2 \%$ with Levobupivacaine $0.25 \%$ \& concluded that both are similar with regard to postoperative analgesia and unwanted postoperative motor blockade in children undergoing minor subumbilical surgery.

Deng et al. (2002) ${ }^{[16]}$ studied to determine minimum local anaesthetic concentration (MLAC) of Ropivacaine for caudal analgesia in children \& concluded that MLAC of Ropivacaine for caudal analgesia under general anaesthesia with $0.5 \mathrm{MAC}$ enflurane during operation was $0.11 \%$ and the EC95 was $0.13 \%$. We decided the caudal concentration of Ropivacaine $0.2 \%$.

Prolongation of caudal analgesia can be achieved by the addition of various adjuvants ${ }^{[6]}$. The additives usually used are: Tramadol, dexmedetomidine, fentanyl, morphine, ketamine, Clonidine.

Opioids are now frequently used caudally because they provide long - acting and efficacious analgesia ${ }^{17-18}$. In contrast to local anaesthetic, opioids do not influence motor and autonomic functions. Opioids can, however, cause respiratory depression, especially during late phases, which limits their use ${ }^{[19]}$.

Vickers et al. ${ }^{[20]}$ compared Tramadol with Morphine to see their effect on respiration. They observed that Tramadol transiently depress the rate of respiration but had no effect on end-tidal carbon dioxide tension. Morphine cause apnoea or considerable depression of ventilation $\&$ concluded that an equianalgesic dose of Tramadol has much less effect on the respiratory center than Morphine. Dexmedetomidine also enhances the effects of local anaesthetics without increasing the incidence of side effects ${ }^{[21]}$.

In our study of Tramadol versus Dexmedetomidine with Ropivacaine was done for postoperative caudal analgesia. It was conducted in 80 patients of 2-10 years with ASA physical status I-II planned for infraumbilical surgeries. They were randomly divided into two groups of 40 patients each.

Group T: $0.5 \mathrm{ml} / \mathrm{kg}$ of $0.2 \%$ Ropivacaine + Tramadol $2 \mathrm{mg} / \mathrm{kg}$

Group D: $0.5 \mathrm{ml} / \mathrm{kg}$ of $0.2 \%$ Ropivacaine + Dexmedetomidine $2 \mu \mathrm{g} / \mathrm{kg}$

Balanced general anaesthesia was given. After Induction, caudal injection of $0.5 \mathrm{ml} / \mathrm{kg}$ of $0.2 \%$ Ropivacaine with Tramadol $2 \mathrm{mg} / \mathrm{kg}$ or Dexmedetomidine $2 \mu \mathrm{g} / \mathrm{kg}$ was given. Intraoperative Pulse, $\mathrm{BP}, \mathrm{SPO}_{2}$ were monitored every $15 \mathrm{~min}$. After extubation, all children were observed postoperatively for $24 \mathrm{hrs}$ for quality \& duration of analgesia (FLACC Score). The duration of analgesia was $12.70 \pm 2.81$ hrs in group T. A.C.Senel et al. $(2001)^{[10]}$ found that duration of analgesia in group Tramadol with Bupivacaine was significantly longer $(13.5 \pm 2.2 \mathrm{~h})$ than in the other two groups $(P<0.05)$.

Meena Doda et al. (2009) ${ }^{[8]}$ also found that of addition of Tramadol with Bupivacaine prolong the duration of analgesia (average $=9.1 \mathrm{hrs}$ ) as compared to group B $(6.3 \mathrm{hrs})$ $(P<0.01)$ but this was less than our study. They have done this study only in 15 patients per group which may be insufficient.

Rukhsana Samad et al. (9/2010 to 3/2011) ${ }^{[9]}$ also found that duration of postoperative analgesia was $17.88 \pm 1.96$ hours in Tramadol - Bupivacaine group as compared to 12.05 \pm 1.63 hours in Ketamine - Bupivacaine group which was very high than our study. This might be due to only inguinoscrotal surgeries.

Malti Pandya et al. (2014) ${ }^{[10]}$ \& N M Solanki et al. (2016) ${ }^{\text {[11] }}$ also found longer duration of analgesia in Tramadol with Local anesthetic group.i.e. $(19.21 \pm 2.25 \mathrm{hrs}) \& 10-18 \mathrm{hrs}$ respectively.

Our study was correlating with the study of I. Saadawy et al. (2009) ${ }^{[12]}$ in their study, the duration of analgesia was $(18.5$ $\pm 2.8 \mathrm{~h}$ ) with Dexmedetomidine $1 \mu \mathrm{g} / \mathrm{kg}$ and Bupivacaine $0.25 \%, 1 \mathrm{ml} / \mathrm{kg}$.

EI-Hennaway AM et al. (2009) ${ }^{[7]}$ found median 16 hrs (1418) \& Vijay G Anand et al. (2016) ${ }^{[22]}$ also found average 14.5 hours duration of postoperative analgesia with Dexmedetomidine $2 \mu \mathrm{g} / \mathrm{kg}$. Mausumi Neogi et al. (2010) ${ }^{[13]}$ found $15.26 \pm 0.86$ hours duration of analgesia with Dexmedetomidine $1 \mu \mathrm{g} / \mathrm{kg}$. So addition of Dexmedetomidine prolongs postoperative duration of analgesia.

In comparision to our study, Mostafa EI Hamamsy et al. (2008) ${ }^{[7]}$ found shorter duration of analgesia i.e. $(347 \pm 13)$ min in group of Dexmedetomidine $1.5 \mu \mathrm{g} / \mathrm{kg} \&(280 \pm 20)$ min in group of Tramadol $2 \mathrm{mg} / \mathrm{kg}$. 
I.Saadawy et al. [12], Mostafa EI Hamamsy et al. ${ }^{[7]}$, Mausumi Neogi et al. ${ }^{[13]}$ \& Vijay G Anand et al. ${ }^{[22]}$ also found that addition of Dexmedetomidine prolong postoperative sedation that resulted in a better quality of sleep. Postoperative sedation score was significantly higher in group $\mathrm{D}$ as compared to group $\mathrm{T}(P<0.01)$.

Like other opioids, Tramadol causes nausea $\&$ vomiting by acting on supraspinal center (CTZ). Meena Doda et al. ${ }^{[8]}$ found that the incidence of nausea \& vomiting was more in group received Tramadol with Bupivacaine (26.67\%) than Bupivacaine alone (20\%).

Rukhsana Samad et al. ${ }^{[9]} \&$ N M Solanki et al. ${ }^{[11]}$ also found that the incidence of nausea \& vomiting was $17.6 \%$ \& $8 \%$ seen in patients received Tramadol.

\section{From our study we have observed following points}

- Postoperative pain score (FLACC Score) - FLACC Score was higher in group $\mathrm{T}$ as compared to group D.

- Duration of caudal analgesia was higher in group D as compared to group T. It was $17.93 \pm 2.65 \mathrm{hrs}$ in group D while it was $12.70 \pm 2.81 \mathrm{hrs}$ in group $\mathrm{T}(P<0.01)$

- Requirement of total no. of doses of Tramadol were high in group $\mathrm{T}$ as compared to group $\mathrm{D}(P<0.01)$

- Postoperative sedation score (Modified Ramsay Score) was higher in group D as compared to group $\mathrm{T}$ in initial postoperative period.

- In group T patients, mild nausea \& vomiting were noted in $12.5 \%$ cases, while in group D patients, there was not any side effect.

Conclusion: This study has shown that the addition of Dexmedetomidine with Ropivacaine significantly prolongs the duration of analgesia as compare to Tramadol for paediatric infraumbilical surgeries \& reduces the postoperative analgesic requirements in 1 st $24 \mathrm{hrs}$ with, initial better quality of sleep. Also no statistically significant haemodynamic differences were found between two groups.

\section{References}

1. De Beer DAH, Thomas M. Caudal additives in children - solutions or problems? Br J Anaesth. 2003; 90(4):48798.

2. Lonnqvist PA, Westrin P, Larsson A, Olsson GL, Lybeck A, Huledal A et al. Ropivacaine pharmacokinetics after caudal block in 1- 8 year old children. British Journal of Anaesthesia. 2000; 85(4):506-11.

3. Wulf H, Peters C, Behnke H. The Pharmacokinetics of Caudal Ropivacaine $0.2 \%$ in Children: A study of infants aged less than 1 year \& toddlers aged 1 - 5 years undergoing inguinal hernia repair. Anaesthesia. 2000; 55:757-760.

4. Prosser DP, Davis A, Booker PD, Murray A. Caudal tramadol for postoperative analgesia in paediatric hypospadias surgery. Br J Anaesth. 1997; 79: 293-296.

5. Senel AC, Akyol A, Dohman D, Solak M. Caudal bupivacaine-tramadol combination for postoperative analgesia in paediatric herniorrhaphy. Acta Anaesthesiol Scand. 2001; 45:786-789.

6. Gune Y, Gunduz M, Unlugene $\mathrm{H}$ et al. Comparison of caudal vs intravenous tramadol administered either preoperatively or postoperatively for pain relief in boys. Paediatric Anaesthesia. 2004; 14:324-328.

7. EI Hamamsy M, Abd-Elrahman A, Abd-Elaziz Essa M, Zakaria D. Prolongation of caudal analgesia in paediatric surgery: comparison between demedetomidine, clonidine, tramadol, and fentanyl. Kasr EL Einy Med J. 2008; 14:1-10.

8. Meena Doda, Sambrita Mukherjee. Postoperative analgesia in children- comparative study between caudal bupivacaine and bupivacaine plus tramadol. India J Anaesth. Aug. 2009; 53(4):463-466.

9. Rukhsana Samad, Tahira Hakim shah. Comparison of caudal tramadol-bupivacaine and ketamine-bupivacaine for postoperative analgesia in children. Journal of Surgery Pakistan (International) 18(2) April - June, 2013.

10. Malti Pandya, Komal tailor, Pragna Vachhrajani. Caudal block using ropivacaine with or without tramadol in children for lower abdominal and lower limb surgery. Int J Med Sci Public Health. 2014; 3(4):461-464.

11. Solanki NM, Engineer SR, Jansari DB, Patel RJ. Comparison of caudal tramadol versus caudal fentanyl with bupivacaine for prolongation of postoperative analgesia in paediatric patients. Saudi J Anaest. 2016; 10:154-160

12. Saadawy I, Boker A, Elshahawy MA et al. Effect of dexmedetomidine on the characteristics of bupivacaine in a caudal block in paediatrics. Acta Anaesthesio Scand. 2009; 53:251-256.

13. Mausumi Neogi, Dhurjoti Prosad Bhattachajee et al. A comparative study between clonidine and dexmedetomidine used as adjuncts to ropivacaine for caudal analgesia in paediatric patients. J Anaesth Clin Pharmacol. 2010; 26(2):149-153.

14. Ray M, Mondal SK, Biswas A. Caudal analgesia in paediatric patients: comparison between bupivacaine and ropivacaine. Indian J Anaesth. 2003; 47:275-8.

15. Ivani G, De Negri P, Lonnqvist PA, Erario L M, Mossetti V, Difilippo A et al. Caudal anaesthesia for minor pediatric surgery: A prospective randomized comparison of ropivacaine $0.2 \%$ paediatr Anaesth. 2005; 15:491-4.

16. Deng XM, Xiao WJ, Tang GZ, Luo MP, Xu KL. The minimum local anesthetic concentration of ropivacaine for caudal analgesia in children. Anesth Analg. 2002; 94:1465-8.

17. Giaufre E, Dalens B, Gombert A. Epidemiology and morbiditsy of regional anesthesia in children: a oneyear prospective survey of the French-Language Society of Pediatric Anesthesiologists. Anesth Analg. 1996; 83:904-912.

18. Boskovski N, Lewinski A, Xuereb J, Mercieca V. Caudal epidural morphine for postoperative pain relief. Anaesthesia. 1981; 36:806-818.

19. Bernatzky G, Jurna I. Intrathecal injection of codeine, buprenorphine, tilidine, tramadol and nefopam depresses the tail-flick response in rats. Eur $\mathbf{J}$ Pharmacol. 1986; 120:75-80.

20. Vickers MD, O TIaherty D, Szekely SM, Read M, Yoshizumi J. Tramadol: pain relief by an opioid without depression of respiration. Anaesthesia. 1992; 47:291-296.

21. Yoshitomi T, Kohjitani A, Maeda S, Higuchi $H$, Shimada M, Miyawaki T. Dexmedetomidine enhances the local anesthetic action of lidocaine via an $\alpha 2 \mathrm{~A}$ Adrenoceptor. Anesth Analg. 2008; 107:96-101.

22. Vijay G Anand, Kannan M, Thavamani A et al. Effects of dexmedetomidine added to caudal ropivacaine in paediatric lower abdominal surgeries. Indian J Anaesth. 2011; 55:340-346. 